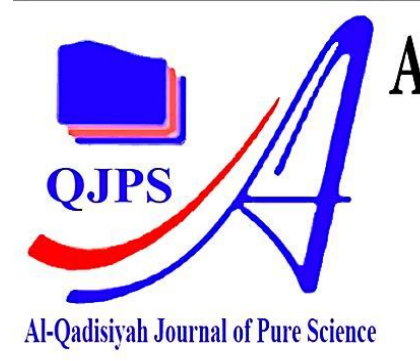

Al-Qadisiyah Journal of Pure Science

ISSN(Printed): 1997-2490

ISSN(Online):

$2411-3514$

DOI: /10.29350/jops.

http:// qu.edu.iq/journalsc/index.php/JOPS

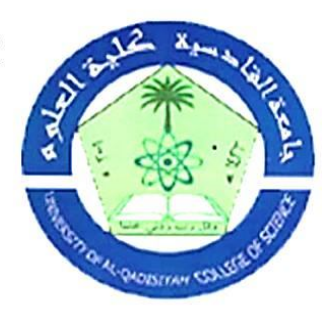

\title{
Egg Shell Powder Reinforced Polypropylene (PP) Composite: Effect of Mechanical and Heat Capacity
}

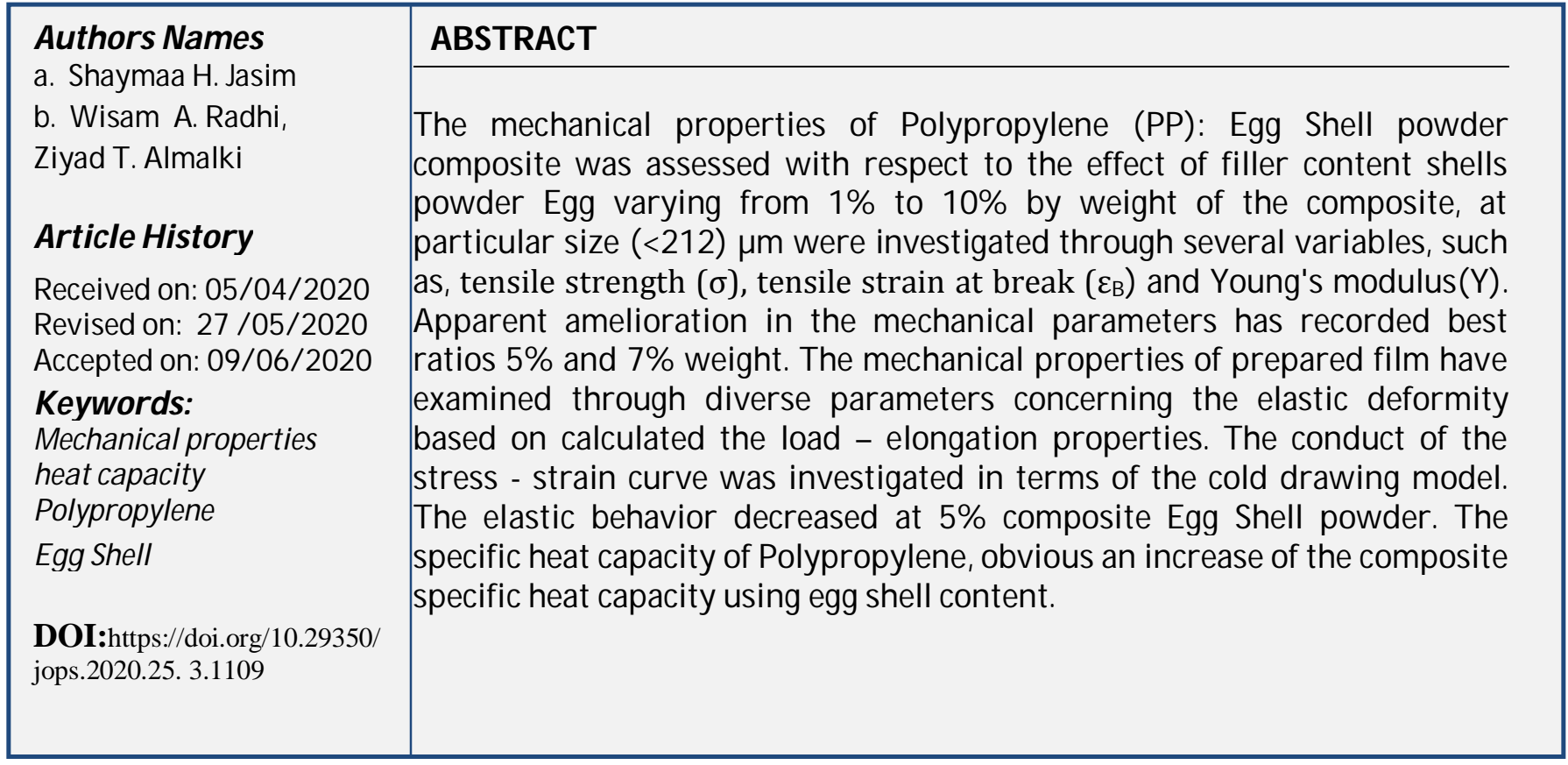

\section{Introduction}

Polypropylene (PP) is widely used as a polymer in the world due to its widespread availability, and low cost of monomer, inexpensive of industrialization, and has distinct features. These characteristics can be enhanced to be suitable for a broad spectrum of applications. Commercial fabrication techniques can be used to modify Polypropylene. Examples of important applications of polypropylene involve possible usages to manufacture pipes, package films, tanks, monofilaments, seat covers, ropes and in washing machines. In 2001, approximately, 30,000,000 tons were consumed in the worldwide. [8,9].

Polypropylene filled with particulate fillers has received much interest both in an academic research and industry due to the polypropylene has a feasibility to allow for accepting various kinds of natural and non-natural fillers. Fillers such as mica, kaolin, $\mathrm{Ca}\left(\mathrm{CO}_{3}\right)_{2}$ and talc have

\footnotetext{
a Department of Physics, College of Education for Pure Science, University of Basrah, Basrah, Iraq E-Mail: shaymaa.jasim@uobasrah.edu.iq

b Department of Chemistry, Polymer research Center, University of Basrah, Basrah, Iraq, E-Mail:

wisam.radhi@uobasrah.edu.iq,ziyad.almlki@yahoo.com
} 
frequently applied to minimize both the productive costs and improvement the thermoplastic features such as strength, rigidity, flexural modulus, hardness, stability, electrical and thermal conductivity. Fillers can be affected by other some properties such as an impact merit and deformability. Features of filler such as type, content, size, interfacial adhesion, bond strength of matrix, surface properties and structure of filler can considerably influence on the filled system. In a highly filled polymer system, no uniformity can occur due to the weak dispersion of filler in system. Astrong interfacial adhesion between filler and matrix probably improve the mechanical properties [1-7, 10-12].

Recently, huge studies have published about addition of fillers to polymer matrixes to develop their properties and to reduce the productive cost. These fillers possess an adverse effect toward plastic properties and this effect leads to decrease the softy of polymer. Examples of known substances as fillers include organic or inorganic materials which are added to polymers either for increasing the volume of plastic material in order to reduce the price or probably improve some mechanical features [13-15]. It can be considered addition process of fillers to polymers easy, fast and inexpensive method to enhance of polymer properties [16,17]. There have been several studies to use egg shell powder as filler in polymer composites [18-23]. The objective of this project is to inspection the influence of egg shell powder on the mechanical properties and heat capacity of polypropylene.

\section{Experimental Procedure}

\subsection{Materials}

The Polypropylene used for this study was supplied by Sabic (Saudi Arabia) and Table (1) presents properties of the polymer which was used in this paper. The used egg shells were bought from local market. Size of particle of egg shell which used in this project was almost $(<212) \mu \mathrm{m}$. Five percentages of egg shell particles $(1,3,5,7$ and 10 weight $\%)$ has used in the Polypropylene compounds.

Table (1): General properties of the Isotactic polypropylene

\begin{tabular}{|c|c|}
\hline property & Value \\
\hline Density, $\mathrm{g} / \mathrm{cm}^{3}$ & 0.908 \\
\hline Melt flow index (MFI) $\mathrm{g} / 10 \mathrm{~min}$ & 11 \\
\hline Glass Transition temperature $\left(\mathrm{T}_{\mathrm{g}}{ }^{\circ} \mathrm{C}\right)$ & 0 \\
\hline Melting point $\left(\mathrm{T}_{\mathrm{m}}{ }^{\circ} \mathrm{C}\right)$ & 170 \\
\hline Degree of crystalline $\%$ & $50-70$ \\
\hline
\end{tabular}

\subsection{Sample preparation}

In this study, five weight percents of egg shell powder (1wt $\%, 3 \mathrm{wt} \%, 5 \mathrm{wt} \%, 7 \mathrm{wt} \%$ and $10 \mathrm{wt} \%$ ) were used in the Polypropylene composites. mixture of egg shell (fine 
powder) with polypropylene were mixed using Rheomix mixer 600 instruments attached to the Haake Rehochard meter with the following conditions; time of mixing $15 \mathrm{~min}$; temperature $160^{\circ} \mathrm{C}$; velocity $32 \mathrm{RPM}$. Next, the final template product was undergone to compress about 5 tons at $175^{\circ} \mathrm{C}$ for 180 seconds in a square frame. The pressure will increase gradually to be 15 tons during a six minutes then the sample sheet will be cooled down to room temperature. This sheet of final product is used to prepare dumbbell specimens as shown in Figure (1). The mechanical test done by instron instrument Zwick/Roel type (BT1-FR2.5 TN.D14) as shown in Figure (2) with these conditions; chart speed (10) $\mathrm{mm} / \mathrm{min}$., crosshead speed $50 \mathrm{~mm} / \mathrm{min}$. The test specimen was positioned vertically in the grips of device then the grips are tightened evenly and firmly to prevent any slippage. The relationship between elongation and load was obtained directly from the device. [24-26].

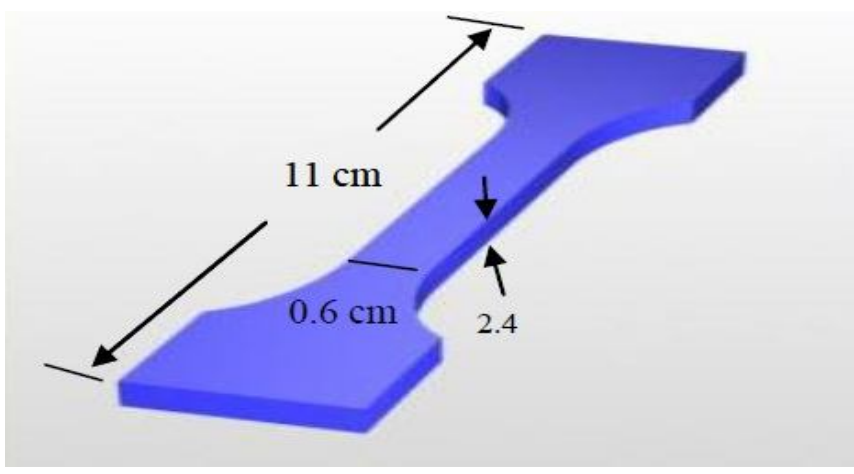

Figure 1: Shows the tensile specimen coupon dimensions centimeters.

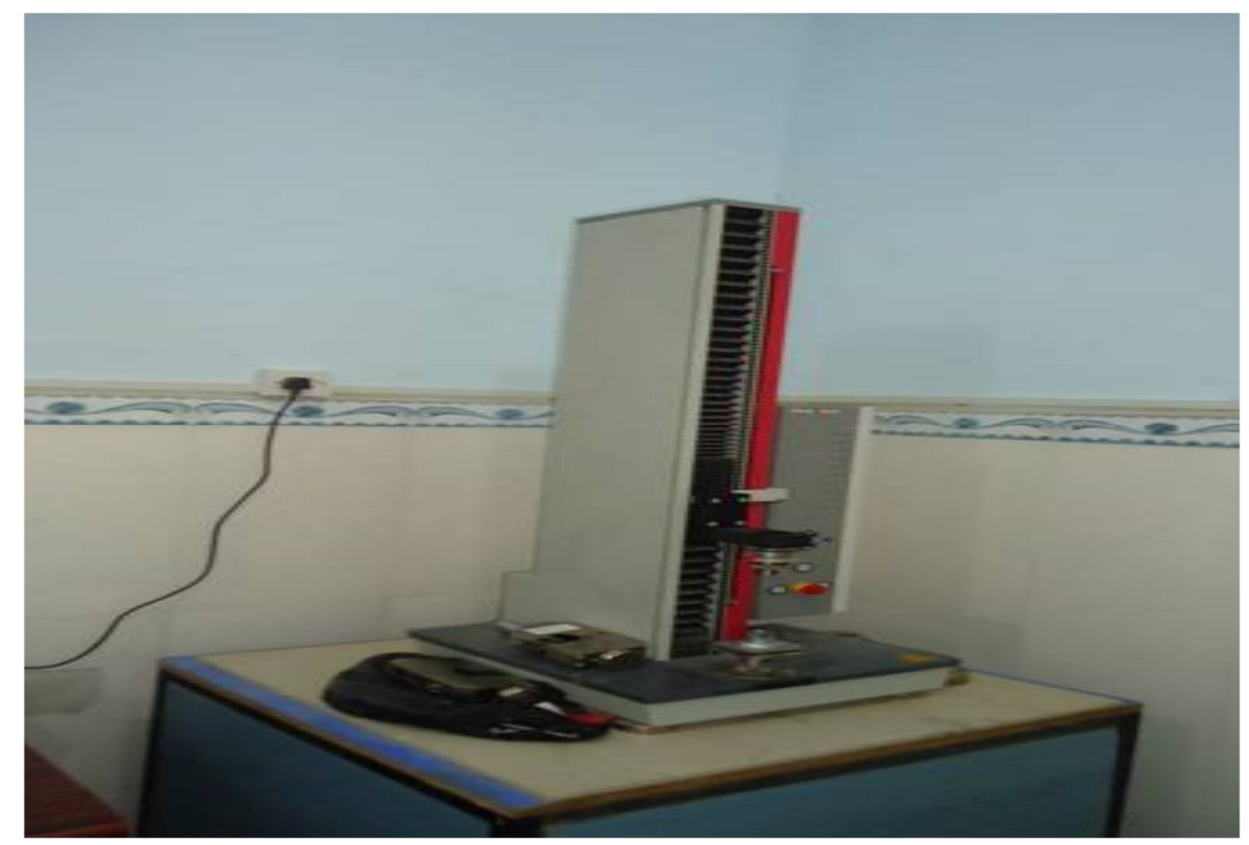

Figure 2: Tensile test of the specimens was carried out with a Zwick/ Roel type [BT1-FR2.5 TN.D14] 


\subsection{Tensile test}

The tensile features have tested depending to the ASTM Standard D-638: Standard check method for tensile merits of materials [27]. The dimensions of the dumbbell-shaped pieces. The amount of strength ( $\sigma)$, tensile strain $(\varepsilon)$ and Young's modulus(Y) were calculated by the following equation [28, 29]:

$\sigma=F / A$

Where $\mathrm{F}=$ force $(\mathrm{N})$, and $\mathrm{A}=$ area of sample $\left(\mathrm{mm}^{2}\right)$.

$\varepsilon \%=\frac{\mathrm{L}-\mathrm{L}_{\mathrm{o}}}{\mathrm{L}_{\mathrm{o}}} * 100$

Where:

L: final length of sample, Lo: original length of sample.

(Young's modulus) Y =stress/ strain ... (3)

\subsection{Differential Scanning Calorimetry (DSC) Analysis:}

The DSC tests were performed using a Shimadzu apparatus DSC-60 model, made in Japan. The samples were sealed in aluminum pans under nitrogen gas in a temperature range (25-125) ${ }^{\circ} \mathrm{C}$ at a calefactory rate of $10^{\circ} \mathrm{C}$ per min.

\section{Results and Discussion}

Figure (3) and table (2) showed that the (stress - strain) curve of polypropylene that loaded with various percentages of egg shell powder was examined at a steady of loading rate at lab temperature. Stress- strain curve has based on the depiction instead of load elongation curve due to it depicts the material features and it was lower relied on the arbitrary select of specimen profile. Based to the break down classification, the stress-strain curve was representing the second behavior of the fracture which called cold drawing [30]. This type contains three parts can be recognized; firstly the linear region, secondly the yield region and thirdly the elongation area until the break. In the first area, the distortion was not very major, Hook's Law was obeyed which states that the immediate and recoverable deformity associated with the bending and stretching inter atomic bonds between the polymer chains. [31]. One of the most significant engineering parameters that reflect the material impedance against disfigurement, and have to be calculated before designing polymer is Young's modulus. Young's modulus can be evaluated from the slope of the portion of the first area, which was found a higher for a sample with a higher extension rate. The variation of Young's modulus against egg shells powder filler was depicted in Figure (4) Young's modulus varied between 256.017MPa to 426.357MPa for egg shell ratio between $1-10 \%$ respectively. It was observed from Figure (4) that Young's modulus decreased at percentages ( $1 \mathrm{wt} \%, 5 \mathrm{wt} \%$ and $7 \mathrm{wt} \%)$, meanwhile, there is an increase in flexibility when hardness was decreased. When at the percentage $(3 \%)$ it was noted that 
increase the value Young's modulus and this pointed out that polymer has good hardness and less flexibility at this percentage. Young's modulus can indicate to high material resistance. Mechanical properties essentially depend upon the molecular behavior; include chemical composition and physical structure. It can be related to the shear component of the applied stress. In the region confined between the proportionality limit and the yield point the deformation in this region is not stantanuosely recoverable, but it's ultimately and can be characterized like straightening out of a coil portion of the molecular chains [32]. The uncoiling mechanism is known as a relatively slow mechanism.

The result of composition of tensile strain at break $\left(\varepsilon_{\mathrm{B}}\right)$ is shown in Figure (5). The maximum tensile comes from a typical homogeneity of filler distribution in the polymer system. The mechanical properties of polypropylene were investigated to show the relationship between the percentage of elongation and the additive concentration. The elongation of the polymer started at $(1 \%)$ around $(38.542 \%)$ which was decreased with increasing of filler ratio; around $(3 \%)$ percentage $(6.901 \%)$. At this point, the polymer offered a few flexibilities and high hardness from the role of egg shell powder which acts to fill the spaces between the main chains of polymer. This also led to limit the movement of the chains and decreased the elongation with increasing of filler ratio at $(5 \%)$ percentage $(51.115 \%)$. Polymeric backbones that were not constrained by any free movement were a short homogeneity in the mixture due to the rigid nature of egg shell powder. This property helps to increase the stiffness of the polymer and decrease elongation.

Figure (6) and table (2) that the maximum tensile strength $\left(\sigma_{M}\right)$ at $7 \%$ is $27.691 \mathrm{MPa}$ so that amount of load tensile strength $\left(\sigma_{\mathrm{M}}\right)$ reversible when increasing the concentration of additive which works egg shell powder to reach $27.228 \mathrm{MPa}$ at $10 \%$ the hardness increases when the polymer and thus the polymeric chains are constrained to decrease its flexibility.

Table 2. Parameters of mechanical properties

\begin{tabular}{|c|c|c|c|}
\hline $\begin{array}{c}\text { Filler content } \\
(\text { wt.\% })\end{array}$ & $\begin{array}{c}\sigma_{\mathrm{M}} \\
(\mathrm{MPa})\end{array}$ & $\varepsilon_{\mathrm{B}} \%$ & $\begin{array}{c}\text { Young modulus } \\
\text { (Mpa) }\end{array}$ \\
\hline 0 & 34.300 & 15.860 & 389.109 \\
\hline 1 & 26.334 & 38.542 & 256.017 \\
\hline 3 & 27.645 & 6.901 & 426.357 \\
\hline 5 & 23.593 & 51.115 & 288.91 \\
\hline 7 & 27.691 & 16.949 & 299.168 \\
\hline 10 & 27.228 & 9.3681 & 379.643 \\
\hline
\end{tabular}




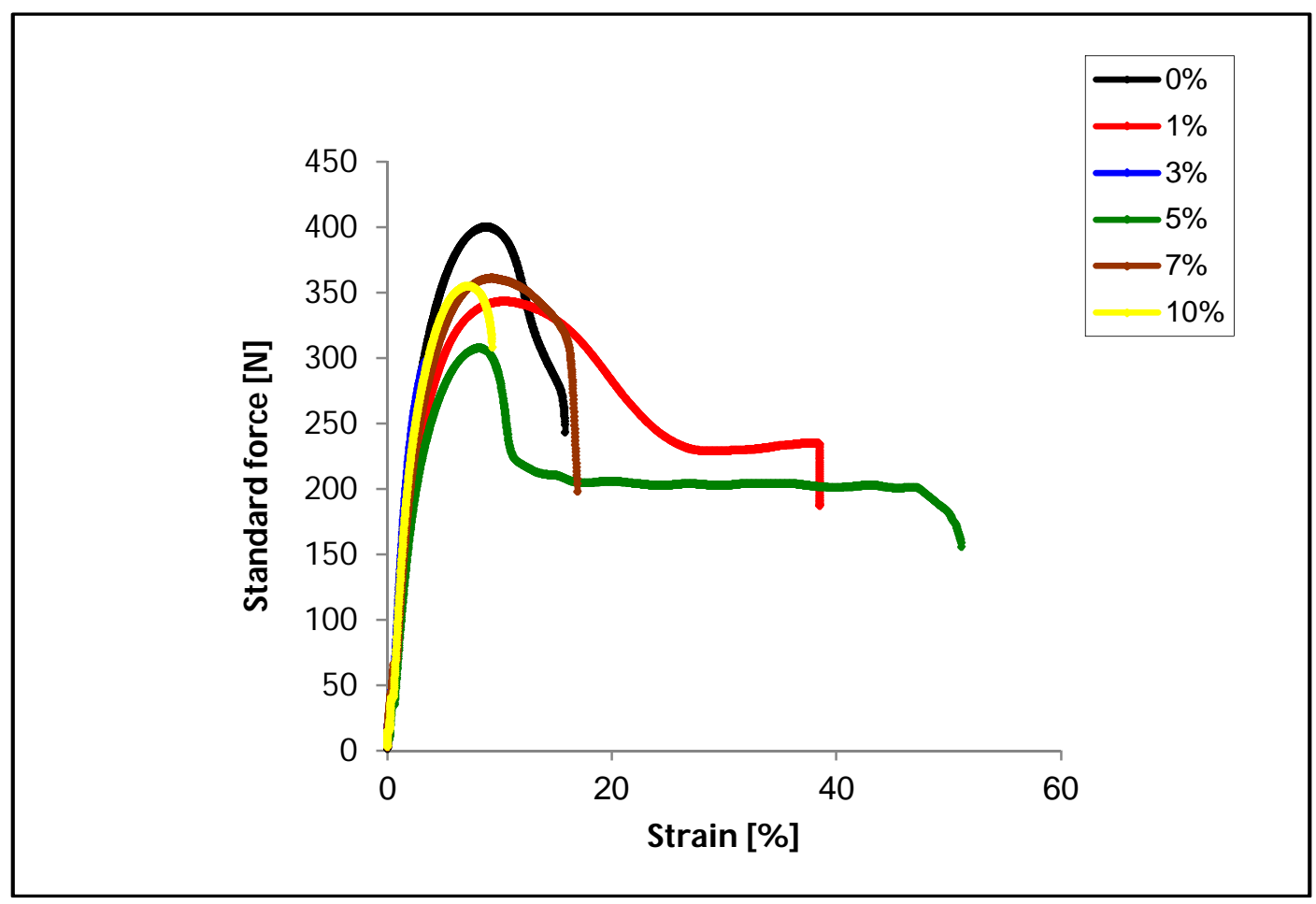

Figure. 3: The stress - strain curves of polypropylene composite with egg shell powder

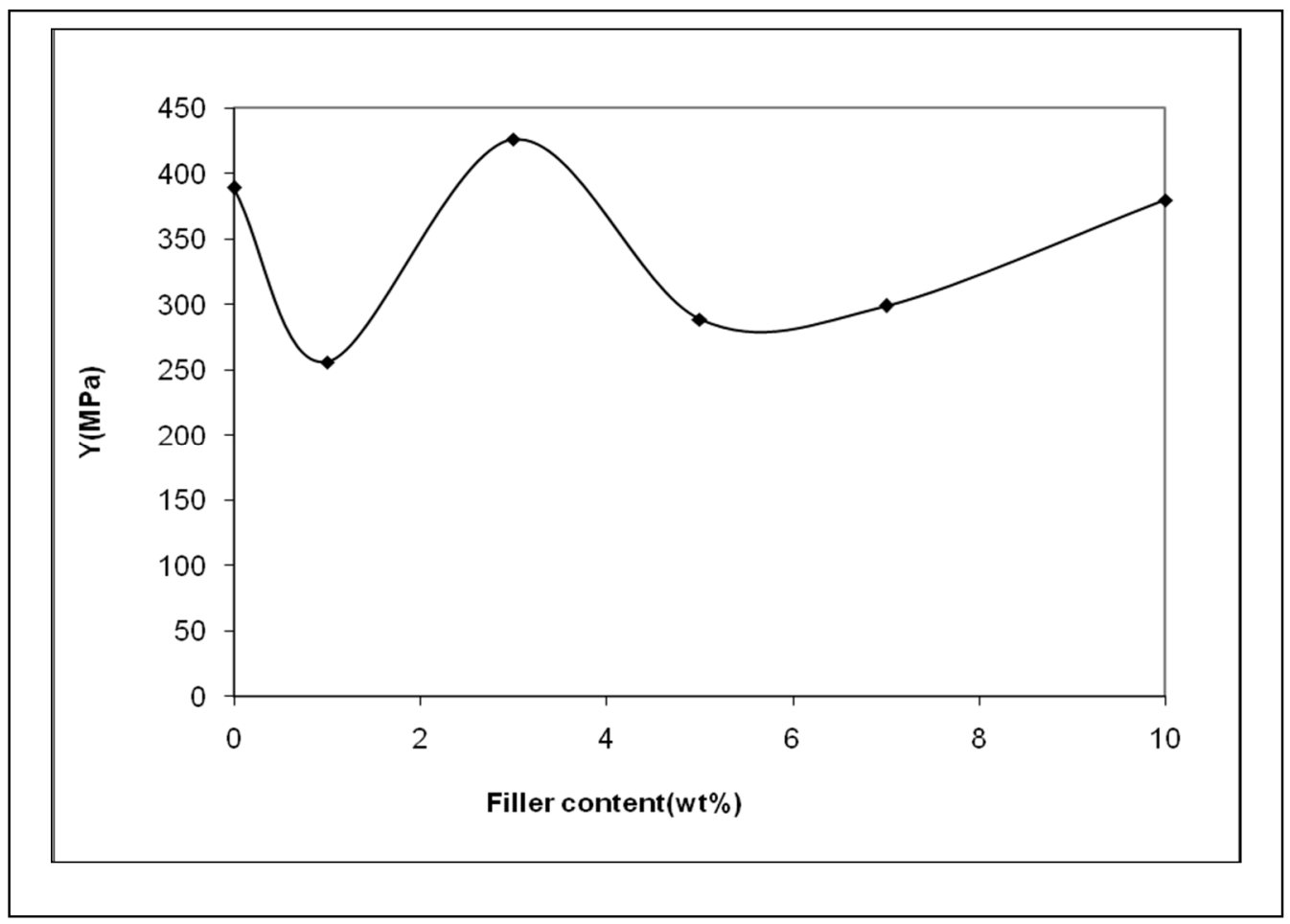

Figure.4: Variation between Young Modules and Filler content (wt.\% ). 


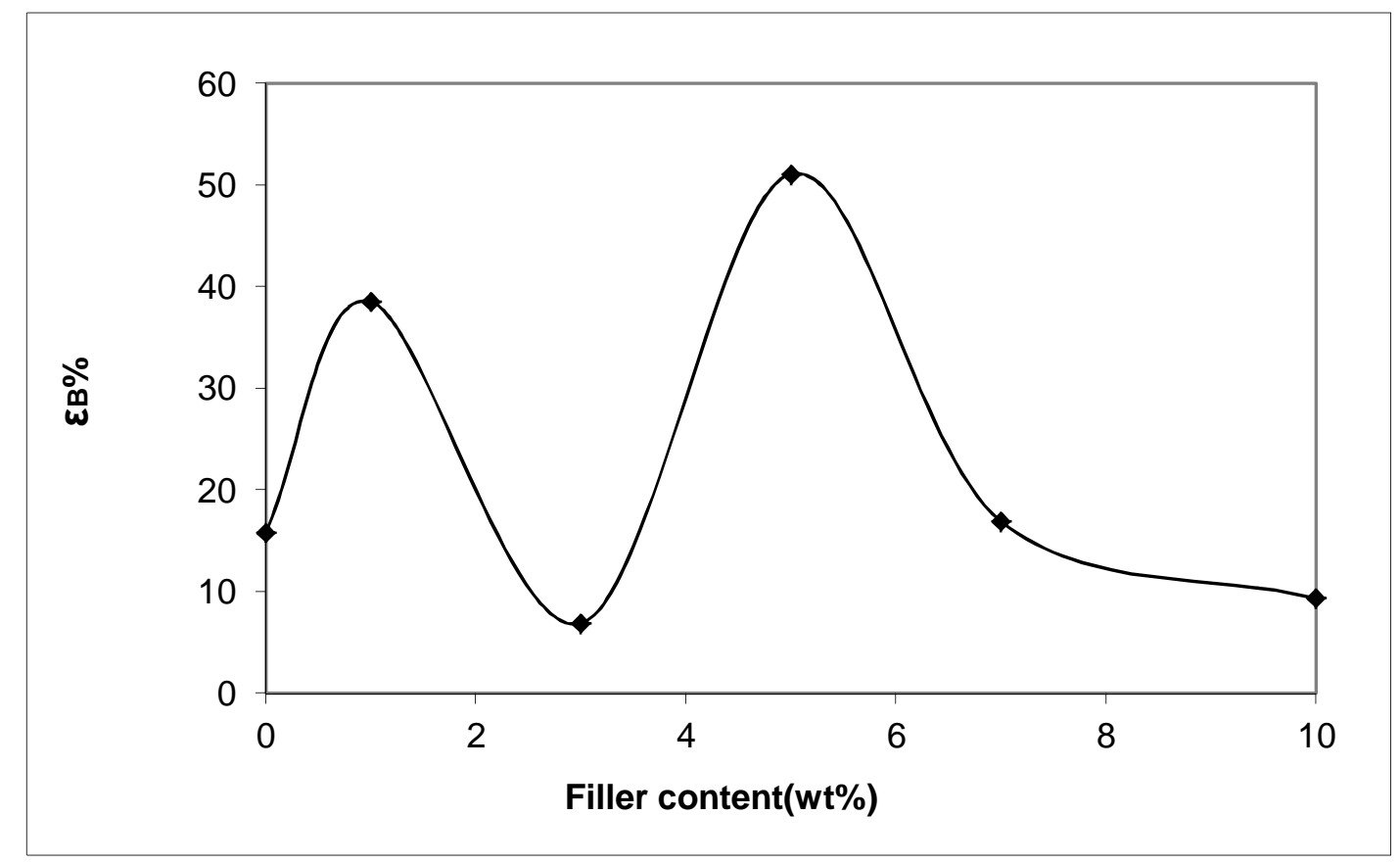

Figure.5: Variation between tensile strain at break and Filler content (wt.\% ).

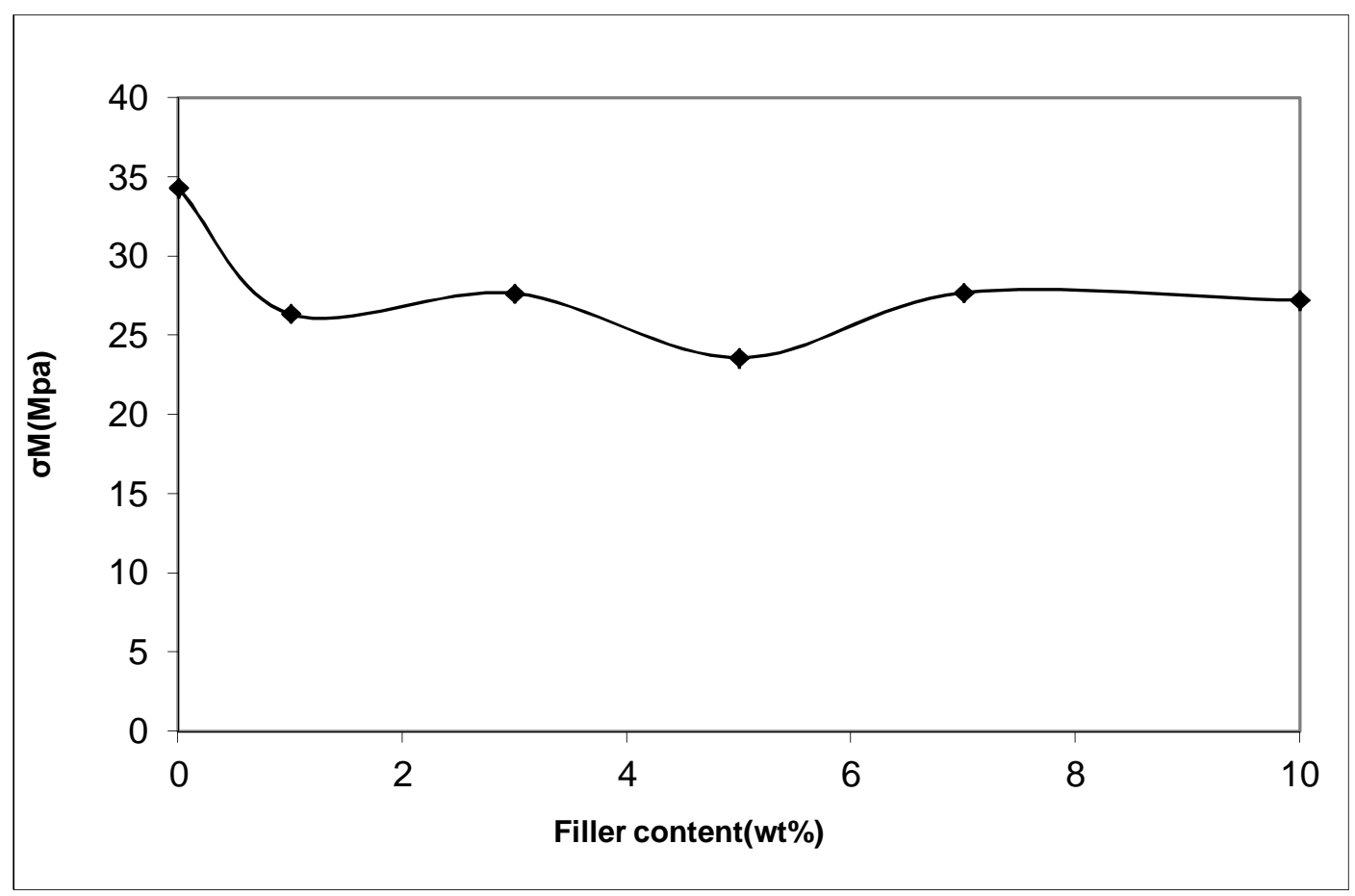

Figure.6: Variation between Tensile strength and Filler content (wt.\%). 
The specific heat capacity of polymer composite with egg shell powder was measured and was shown in Table 3. This was associated to the high value of powder particles heat capacity. The specific heat capacity of compounds as a function of temperature in the range $40^{\circ} \mathrm{C}$ to $100^{\circ} \mathrm{C}$ is plotted in Figure (7). The heat capacity increases with temperature for every composite. The specific heat capacity of polymer increases significantly with temperature. In crystalline composite, the heat capacity increases until reaches to a plateau according to the Dulong and Petit value, that is a good approximation for solids at room temperatures $\left(300^{\circ} \mathrm{K}\right)$. In glasses, the heat dependence of heat capacity will be more evident as a result of the larger molecular movability. In our case, as the egg shell powder content increases, the heat capacity growth linearly with temperature. This practical conduct probably due to the increasing proportion of a disordered-like behavior for the highly loaded compounds. The effect of temperature on the specific heat capacity shows clearly the contribution of the egg shell particles network to the compounds specific heat capacity. Specific heat capacities of composites at $60{ }^{\circ} \mathrm{C}$ are shown on Figure(8)as a function of egg shell powder weight content. We perceive an increase of the composite specific heat capacity with egg shell content [33].

Table 3. Specific heat capacity at $60{ }^{\circ} \mathrm{C}$

\begin{tabular}{|c|c|}
\hline Filler \% & $\begin{array}{c}\mathrm{C}_{p} \text { (J/kg.C) } \\
\text { at 60 C }\end{array}$ \\
\hline 0 & 1485 \\
\hline 1 & 1900 \\
\hline 3 & 1503 \\
\hline 5 & 1752 \\
\hline 7 & 1963 \\
\hline 10 & 1812 \\
\hline
\end{tabular}




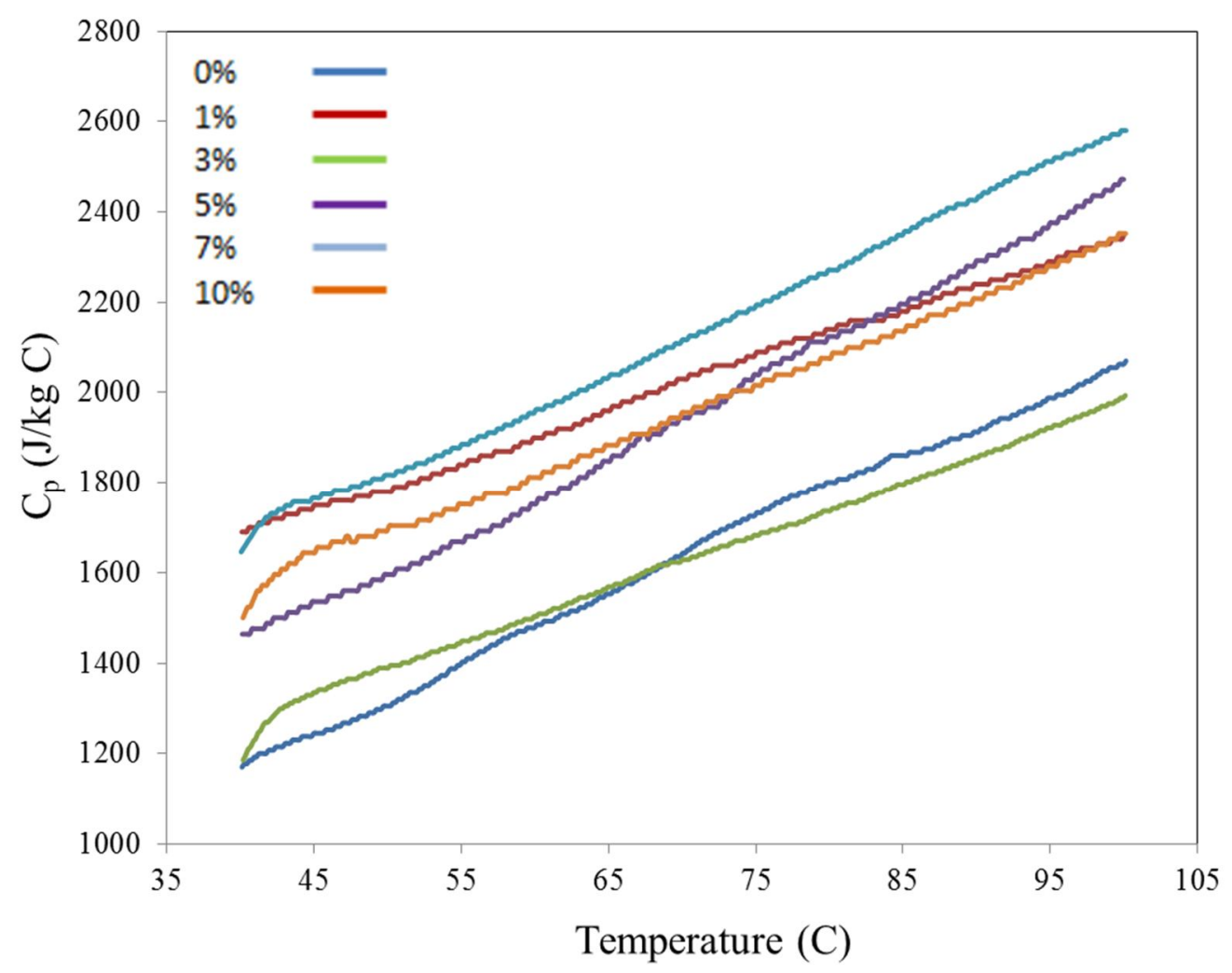

Figure.7: The composites specific heat capacity with temperature from $40^{\circ} \mathrm{C}$ to $100{ }^{\circ} \mathrm{C}$.

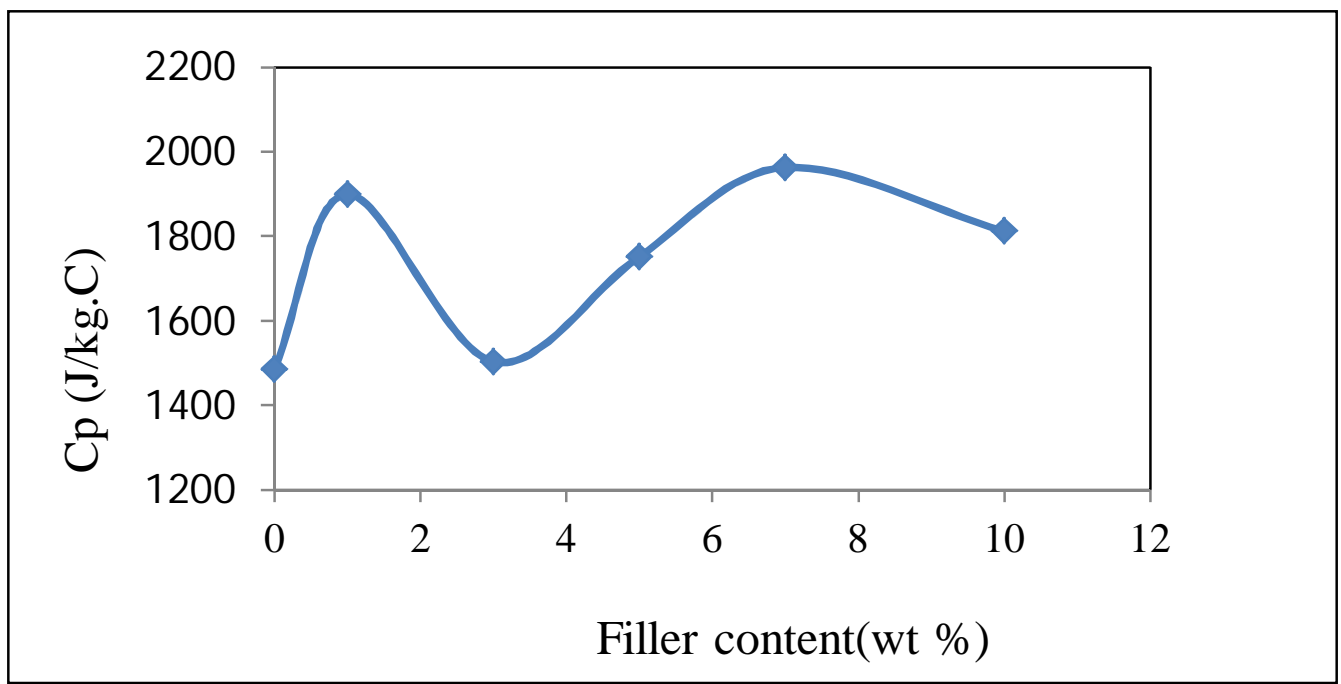

Figure.8: Specific heat capacity versus filler percentages 


\section{Conclusion}

Mechanical properties of Polypropylene were changed by adding (egg shell powder) with different weight percentage. Polymer matrix was decreased by stiffer material (egg shells powder). This interprets the weekend perceived in mechanical features above than $7 \%$ percentage. Therefore, Polypropylene with $5 \%$ and $7 \%$ egg shell powder is recommended for industrial applications, and the high specific heat capacity at $7 \%$.

\section{References}

[1]. M. Denac, V. Musil, I. Smit, F. Ranogajec, Effects of talc and gamma irradiation on mechanical properties and morphology of isotactic polypropylene/talc composites, Polym. Degrad. Stab., (82) (2003),263-270.

[2]. M. Eroglu, Effect of Talc and Heat Treatment on the Properties of Polypropylene/ EVA Composite, International Journal of Science \& Technology, 2(1)( 2007), 63-73.

[3]. S.D. Guiterrez, M.A.R. Perez, J.A. Saja, J.I. Velasco, Dynamic mechanical analysis of injectionmoulded discs of polypropylene and untreated and silane-treated talc-filled polypropylene composites, Polym., (40)(1999), 5345-5353

[4]. R.S. Hadal, A. Dasari, J. Rohrmann, R.D.K. Misra, Effect of wollastonite and talc on the micromechanisms of tensile deformation in polypropylene composites, Mater. Sci. Eng. A., (372) (2004), 296-315.

[5]. Y.W. Leong, Z.A.M. Ishak, A. Ariffin, Mechanical and thermal properties of talc and calcium carbonate filled polypropylene hybrid composites, J. Appl. Polym. Sci., (91) (2004), 3327-3336.

[6]. W.G. Perkins, Polymer toughness and impact resistance, Polym. Eng. Sci., 39 (1999), 24452460 .

[7]. H.G.B. Premalal, H. Ismail, A. Baharin, Comparison of the mechanical properties of rice husk powder filled polypropylene composites with talc filled polypropylene composites, Polymer Testing, (21) (2002), 833-839.

[8]. W. A. Radhi, S. M-H. Ismael and K. A. Hussain, Use a Quantum Chemical to Study the Correlation between Intrinsic Viscosity of Polypropylene in three solvents and structure properties, International Journal of ChemTech Research, 8(10) (2015),361-366.

[9]. N. Singh, S. Dutta., Reinforcement of Polypropylene Composite System via Fillers and Compatibilizers, Open Journal of Organic Polymer Materials, (3 )(2013), 6-11.

[10]. A.L.N. Silva, M.C.G. Rocha, M.A.R. Moraes, C.A.R. Valente, F.M.B. Coutinho., Mechanical and rheological properties of composites based on polyolefin and mineral additives". Polymr Testing., 21(1) (2002), 57-60. 
[11]. W. Qui, K. Mai, H. Zeng, Effcet of silane grafted polypropylene on the mechanical properties and crystallization behavior of talc/ polypropylene composites, J. Appl. Polym. Sci., (77) (2000), 2974-2977.

[12]. C.A. Wah, L.Y. Choong, G.S. Neon, Effects of titanate coupling agent on rheological behaviour, dispersion characteristics and mechanical properties of talc filled polypropylene, Eur. Polym.J., (36)(2000),789-801 .

[13]. W. A. Radhi, Effect of Rockwool Fibers on the Mechanical Properties and Average Time of Burning of Low Density Polyethylene, Journal of Basrah Researches ((Sciences)), 43 (1A), (2017),52-61.

[14]. W.Callister," Materials science \& Engineering an introduction ",Jone Wiley ,6th Ed, (2003).

[15]. A. J. Mohammed, study of the mechanical properties of high density polyethylene (hdpe) composites with alum powder, Journal of Basrah Researches ((Sciences)). ,42 (2 A), (2016),130138.

[16]. H. Salmah, C.M. Ruzaidi and A.G. Supri, Compatibilization of Polypropylene/ Ethylene Propylene Diene Terpolymer/Kaolin Composites: The effect of Maleic Anhydride -grafted Polypropylene, Journal of Physical Science, 20(1)(2009), 99-107.

[17]. A.S. Luyt, V.G. Geethamma, Effect of oxidized paraffin wax on the thermal and mechanical properties of linear low-density polyethylene-layered silicate Nan composites, Polymer Testing 26(4) (2007) 461-470,.

[18]. R.A. Nasif, Preparation and Characterization of Eggshell powder (ESP) and study its Effect on unsaturated Polyester Composites Material, IRAQI JOURNAL OF APPLIED PHYSICS, 11(1) (2015), 25-28.

[19]. A.A. Hussein, R. D. Salim and A. A. Sultan, Water absorption and mechanical properties of high - density polyethylene/ egg shell composite, Journal of Basrah Researches ((Sciences)) , 37 (3A), (2011),36-42.

[20]. H. A. Hamadi, N. A. Abdullah, A. T. Battor ,A. K. Mohammad and Abdullah A. Hussien, Mechanical Properties of Poly vinyl Chloride/ Egg Shell Composite, Misan Journal for Academic Studies , 11 ( 21) (2012),71-78.

[21]. B. Ashok, S. Naresh, K. O. Reddy, K. Madhukar, J. Cai, L. Zhang, A. V. Rajulu, Tensile and Thermal Properties of Poly(lactic acid)/ Egg Shell Powder Composite Films, International Journal of Polymer Analysis and Characterization,19(3) (2014),245-255.

[22]. S. C. Nwanonenyi, C.O. Chike-Onyegbula, "Water Absorption, Flammability and Mechanical Properties of Linear low density polyethylene/ egg shell composite", Academic Research International,4(1)(2013).352-358.

[23]. Y. Feng , B. Ashok , K. Madhukar , J. Zhang , J. Zhang , K. O. Reddy and A. V. Rajulu, Preparation and Characterization of Polypropylene Carbonate Bio-Filler (Eggshell Powder) 
Composite Films, International Journal of Polymer Analysis and Characterization, (19)(2014),637-647.

[24]. Nadhim A. Abdullah, Ahmed J. Mohammed, Ibrahim K. Ibrahim and Faise J. Mohammed, Study the effect of the adding of Ash of Palm Fronds on the Mechanical Properties for High Density Polyethylene (HDPE), Advances in Life Science and Technology, (66)(2018), 74-81.

[25] .W. A. Radhi, Sh. H. Jasim, R. M. Shaban, I. K. Ibrahem and F. J. Mohammed. A Study of Tensile Strength Properties and Flame resistance of ( High Density Polyethylene / shells powder Cocos nucifera) Composite, Journal of Basrah research((science)), 40 (3A0) (2014),48-58.

[26]. W. A. Radhi, Sh. H. Jasim, I. K. Ibrahem and F.J. Mohammed, Improved mechanical properties and flame retardant of low density polyethylene (LDPE) with adding different percentages of powder carboxymethyl-cellulose (CMC). Wasit Journal for Science \& Medicine, 8(3)(2015), 48-57.

27. American Society for Testing and Materials, "Standard test method for tensile properties of plastics," ASTM standard ASTM D638-08, ASTM, Philadelphia, PA., (2008).

28. W. A. Radhi , Sh. H. Jasim, Z. T.Almalki and F. J. Mohammed, American Journal of Engineering Research (AJER), Study the effect of Juglans regia husk powder addition on the Tensile Strength Properties of High Density Polyethylene (HDPE), 8(5) (2019),344-349.

29. W. A. Radhi , Sh. H. Jasim, Z. T.Almalki, Ibrahem K. Ibrahem and F. J. Mohammed, Effect of Punica garantum peel powder on the tensile strength properties of Low Density Polyethylene, Journal of Scientific and Engineering Research 5(7)( 2018),249-255.

30. Mark, H.F.: Encyclopedia of Polymer Science and Technology, 5 (1966).

31. A. A. Hussien, A. A.Sultan and Q. A. Matoq, "Mechanical behaviour of Low Density Polyethylene / Shrimp Shells Composite", Journal of Basrah Researches Sciences, 37 (3A) (2011),5-11,

32. F.Garten, A. Hilberer,F.Cacialli, E. Esselink ,Y.vandam ,B.Schlatmann , R.H.Friend ,T.M. klapwijk, G hadziioannou, Efficient blue LEDs from a partially conjugated Si-containing PPV copolymer in a double-layer configuration, Advanced materials, 9(2)(1997),127-131.

33. N. Tangboriboona, W.Pannangpetcha, K. Aranyika, K.Petcharoenb and A. Sirivatb, Embedded Eggshells as a Bio- Filler in Natural Rubber for Thermal Insulation Composite Foams, Progress in Rubber, Plastics and Recycling Technology, 31 ( 3) (2015),189-205. 